\title{
SCHISTOSOMA MANSONI: ASPECTOS QUANTITATIVOS DA FER'TILIDADE E SOBREVIDA DE VERMES ORIUNDOS DE CERCÁRIAS IRRADIADAS COM 3 KRAD, EM CAMUNIDONGOS
}

\author{
Gileno de Sá CARDOSO ${ }^{(1)}$ \& Paulo Marcos Zech COELIIO ${ }^{(2)}$
}

\begin{abstract}
RESUMO
Quatro grupos de camundongos albinos (Mus musculus) nāo isogênicos foram infectados transcutaneamente com cerca de 450 cercárias (das cepas LE e SJ do $\mathbf{S}$. mansoni) não irradiadas (grupos controles) e irradiadas com $3 \mathrm{Krad}$ de radiaçāo gama proveniente de cobalto-60, com a finalidade de observar o efeito da irradiação gama sobre a fertilidade das fêmeas e a sobrevida dos vermes no sistema porta. A partir do $33^{\circ}$ dia ocorre uma ccrta estabilidade na população dos vermes sobreviventes, ficando esta população constante, notadamente em relação à cepa LE, até o final das observações ( $90^{\circ}$ dia). Concluiu-se que esta dose de radiação gama impede a produção de ovos dos vermes em 98,1\% dos camundongos infectados, sendo mortos todos os ovos detectados; as fêmeas são mais resistentes à irradiação e o efeito desta sobre a mortalidade dos machos somente se torna estatisticamente significativo a partir do $61^{\circ}$ dia de infecção. O longo tempo de permanência de vermes adultos irradiados estéreis no sistema porta de camundongos e o seu provável envolvimento no desenvolvimento de imunoproteção, tipo imunidade concomitante sem as implicações imunopatológicas para o hospedeiro, são discutidos nesse trabalho.
\end{abstract}

UNITERMOS: Schistosoma mansoni: Ccrcárias irradiadas; esterilização de vermes.

\section{INTRÒDUÇÃO}

Alguns autores, utilizando cercárias de Schistosoma mansoni irradiadas com diferentes tipos de radiação ionizante na dose aproximada de $3 \mathrm{Krad}$, abordaram os efeitos da radiação sobre a fertilidade e sobrevida dos vermes, delas oriundos, no sistema porta de camundongos.

VILLELLA et al. ${ }^{12}$ verificaram que camundon-

(1) Laboratório de Parasitologia, Departamento de Morfologia, Centro de Ciências Biológicas e da Saúde, Universidade Federal de Sergipe, Aracaju, Sergipe, Brasil.

(2) Departamento de Parasitologia e Grupo Interdepartamental de Estudos sobre Esquistossomose (GIDE), Instituto de Ciências Biológicas, Universidade Federal de Minas Gerais, BII/MG-Brasil.

Endereço para correspondência: GIDE-ICB/UFMG. CP 2486. 30161 Belo Horizonte, MG, Brasil.

Abreviaturas usadas neste trabalho: GIDE = Grupo Interdepartamental de Estudos sobre Esquistossomose; ICB = Instituto de Ciências Biológicas da Universidade Federal de Minas Gerais; CDTN = Centro de Desenvolvimento da Tecnologia Nuclear; NUCLEBRÁS = Empresas Nucleares Brasileiras S.A. 
gos inoculados com cercárias de S. mansoni, cepa de Porto Rico mantida cm Biomphataria glabrata, irradiadas com $3.000 \mathrm{rep}$ de radiação gama proveniente de $\mathrm{Co}-60$, desenvolveram imunidade a uma reinfecção com cercárias não irradiadas. Esses autores também observaram que os poucos vermes oriundos das cercárias ir radiadas com esta dose de radiaçáo eram sexualmente estéreis. PERLOWA(JORA-SZUMLEWICZ' observou que os vermes cvoluídos de cercárias de S. mansoni irradiadas com $2.000 \mathrm{r}$ de raios $X$, persistem no sistema porta de camundongos até o $288^{\circ}$ clia de obscrvação.

No presente estudo, procurou-se investigar - eleito da dose de 3 Krad de radiação gama proveniente de $C(0-6)$ sobre a evoluçáo dos paratsitos $\mathrm{cm}$ camundongos infectados transculancamente com cerca de 450 cercárias, das cepas LE e SJ do S. mansoni. Essa retomada dos cstudos com a dose de 3 Krad é justificada pelo fato de que a permanência de vermes sexualmente estéreis no sistema porta de camundongos pode ler alguma implicaçáo no desenvolvimento de imunoproteçio, tipo imunidade concomilante, sem as implicaçoes para o hospedeiro decorrentes da presença de ovos viátveis.

\section{MATERIAL E MÉTODOS}

\section{Animais e parasitos}

Camundongos albinos (Mus musculus) nīo isogênicos, fêmeas, com ecrca de 30 dias de nascidos, foram infectados transcutancamente com cerca de 450) cercárias de Schistosoma mansoni (cepa LE, de Belo Horizonte, mantida no GIDE em Biomphalaria glabrata há mais de 25 anos e cepa S.J, de São José dos Campos-SP, miantida do ICB cm B. glabrata com repassagens sucessivas $\mathrm{cm}$ Biomphalaria tenagophila há mais de 10 anos). Os planorbídeos, nascidos e criados $\mathrm{cm}$ laboratório (segundo técnica de FREITAS ${ }^{4}$ ), foram infectados seguindo-se a lécnicá descrita por PELLEGRINO \& KATZ ${ }^{5}$.

\section{Irradiação das cercárias e infeção dos camundongos}

Quatro grupos experimentais foram definidos utilizando-se cercárias näo irradiadlas (grupos controles com 84 camundongos de cada cepa de S. mansoni) o irradiadas com 3 Krad (com 90 camundongos para cada cepa de S. mansoni), dass duas cepas. As amostras a serem irradiadas cram transportadas para o CDTN da NUCLEBRÁS, onde cram expostas à radiaçāo gama proveniente de cobalto-60, sendo a dose de irradiação equivalente ao tempo de exposição das cercárias a essa fonte de radiação. Os animais foram infectados transculancamente (cerca de 450 larvas irradiadas ou normais), segundo BARBOSA ct al.'

\section{Recuperação dos parasitos da pele e pulmóes}

Os parasitos foram recuperados da pele e pulnōes conforme lécnica de BARBOSA et al.!

\section{Pesquisa de ovos}

A partir do 40" dia pós-inleç̧ão, foram fcitas pesquisas de ovos de S. mansoni em fragmentos do intestino delgado e ligado dos camundongos cxpostos às cercárias não irradiadas e irradiadas com $3 \mathrm{Krad}$, de ambals as cepas. O oograma foi feito seguindo-se a técnica de PELLEGRINO et al.".

\section{Duração total do experimento}

Os grupos con cercirias irradiadas com 3 Krad, de ambas as cepas, foram sacrilicados e examinados no $90^{\circ}$ dia após infeçūo, que foi o último dia de observação.

\section{Análise dos resultados}

Na análise estatística dos resultados foi utilirado o método da análise de variancia, trabalhando-se com proporçóes bascadas no rendimento ecrcárias/vermes, ajustadas pelo método da transformaçáa arco-seno ou angular, de acordo com SNEDECOR \& COCHRAN"

\section{RESULTADOS}

\section{Oograma}

() oograma delectou a presença de ovos em todos os estádios cvolutivos no fígado e intestino de todos os camundongos dos grupos controles (no 40" c 47" dia após a inleção), enquanto nos camundongos expostos a cercárias irradiadas com $3 \mathrm{Krad}$ somente foram detectados poncos ovos morlos em apenas dois (2) infectados com a cepa LE (no 47" c 61" dias após a infecção). Foram examinados um total de 105 camundongos cxpos- 


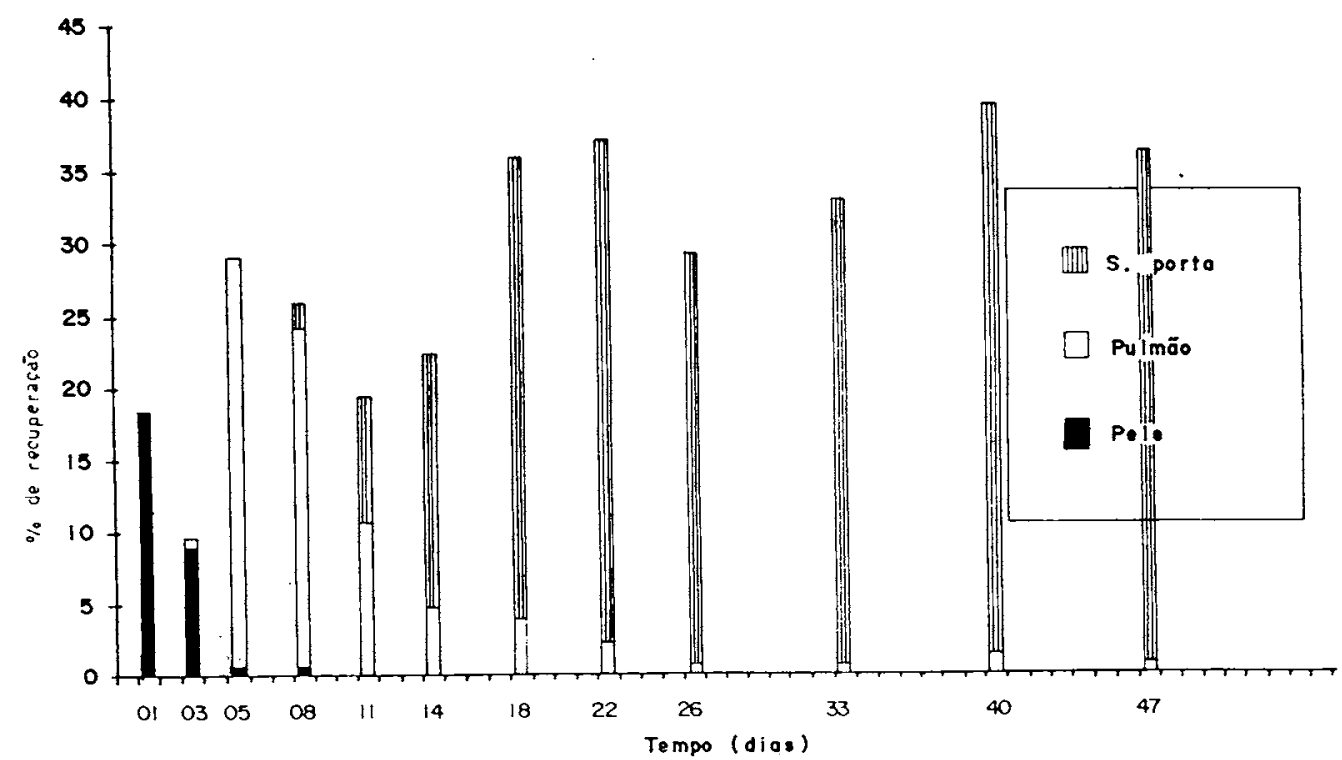

GRÁFICO 1 - Porcentagens médias de recuperação total de parasitos da pele, pulmóes e sistema porta, oriundos de cercárias, da cepa LE do S. mansoni, não irradiadas (controle), obtidas em camundongos infectados transcutaneamente com cerca de 433 cercárias.

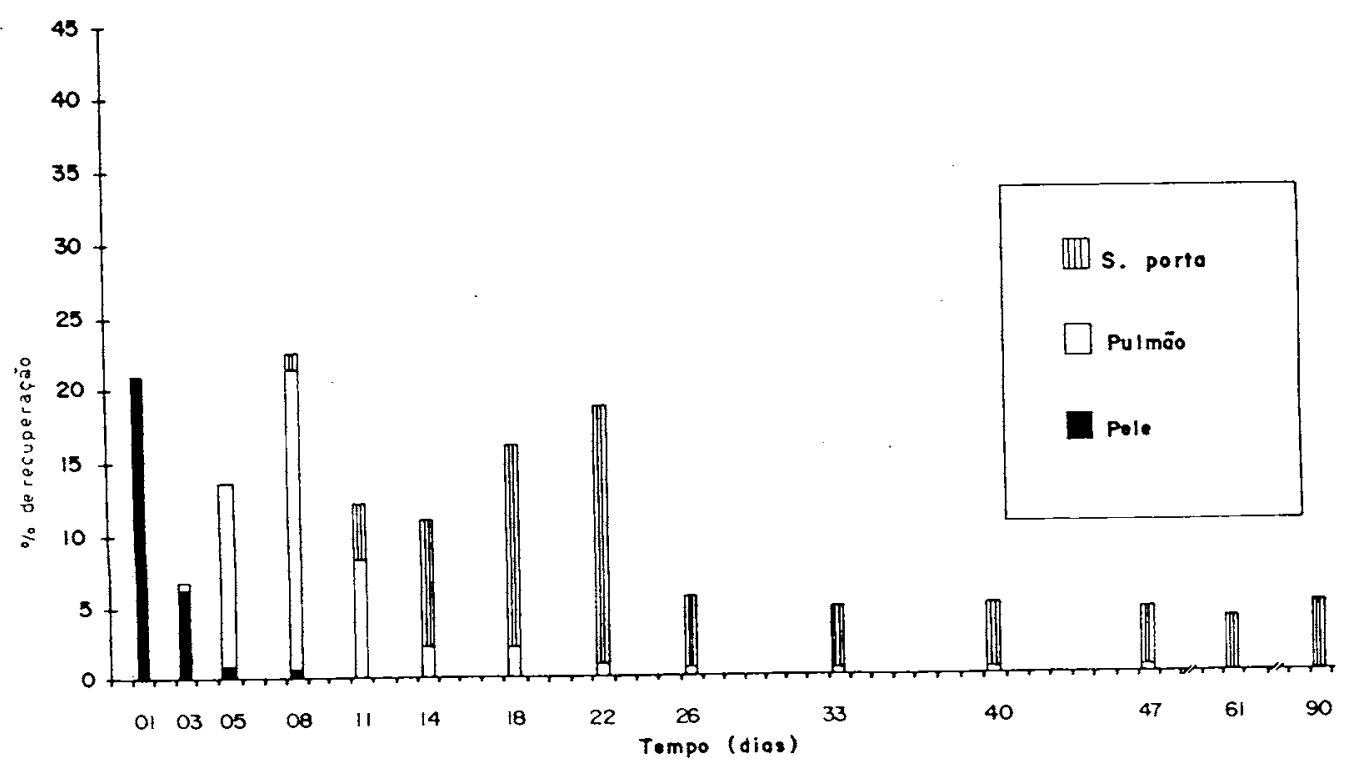

GRÁFICO 2-Porcentagens médias de recuperação total de parasitos da pele, pulmões e sistema porta, oriundos de cercárias, da cepa LE do S. mnnsont, irradiadas com $3 \mathrm{Krad}$, obtidas em camundongos infectados transcutaneamente com cerca de 394 cercárias. 


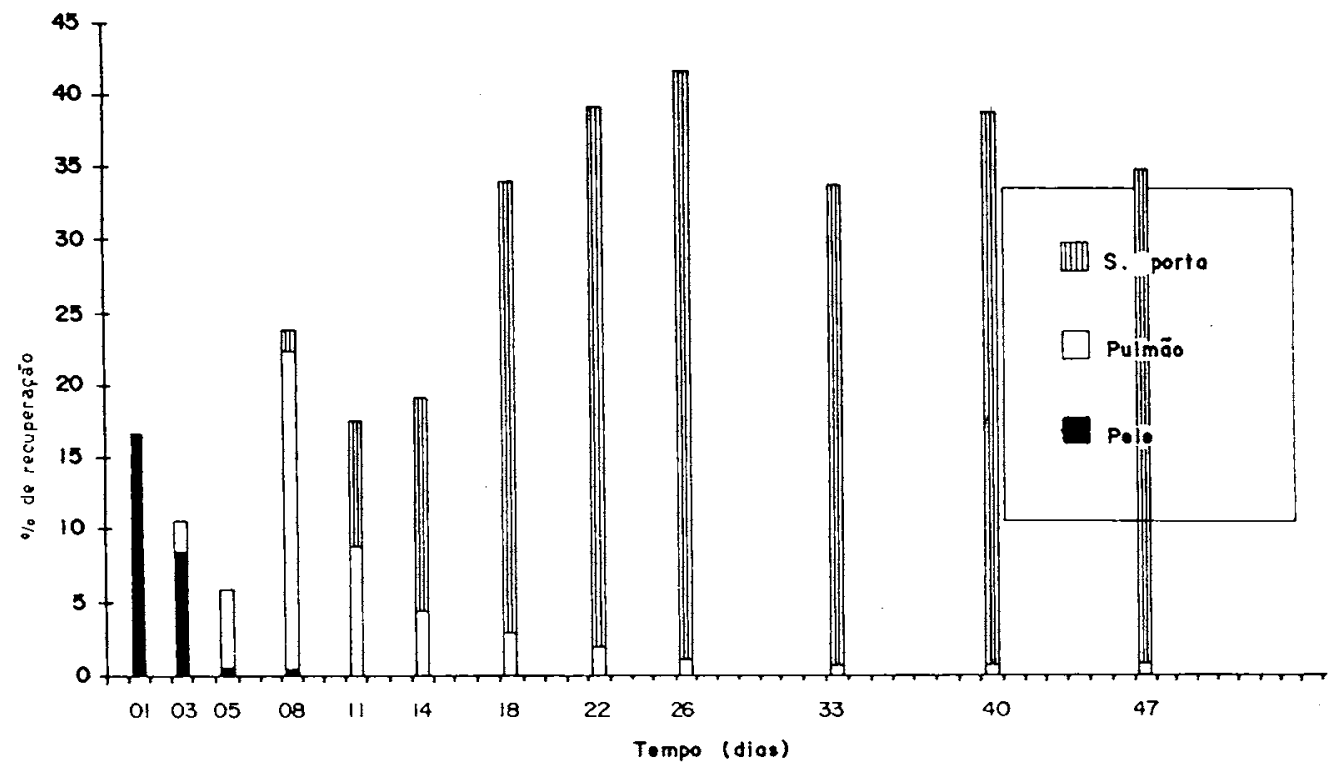

GRÁFICO 3 - Porcentagens médias de recuperação total de parasitos da pele, pulmões e sistema porta, oriundos de cercárias, da cepa SJ do S. mansoni, não irradiadas (controles), obtidas em camundongos infectados transcutaneamente com cerca de 409 cercárias.

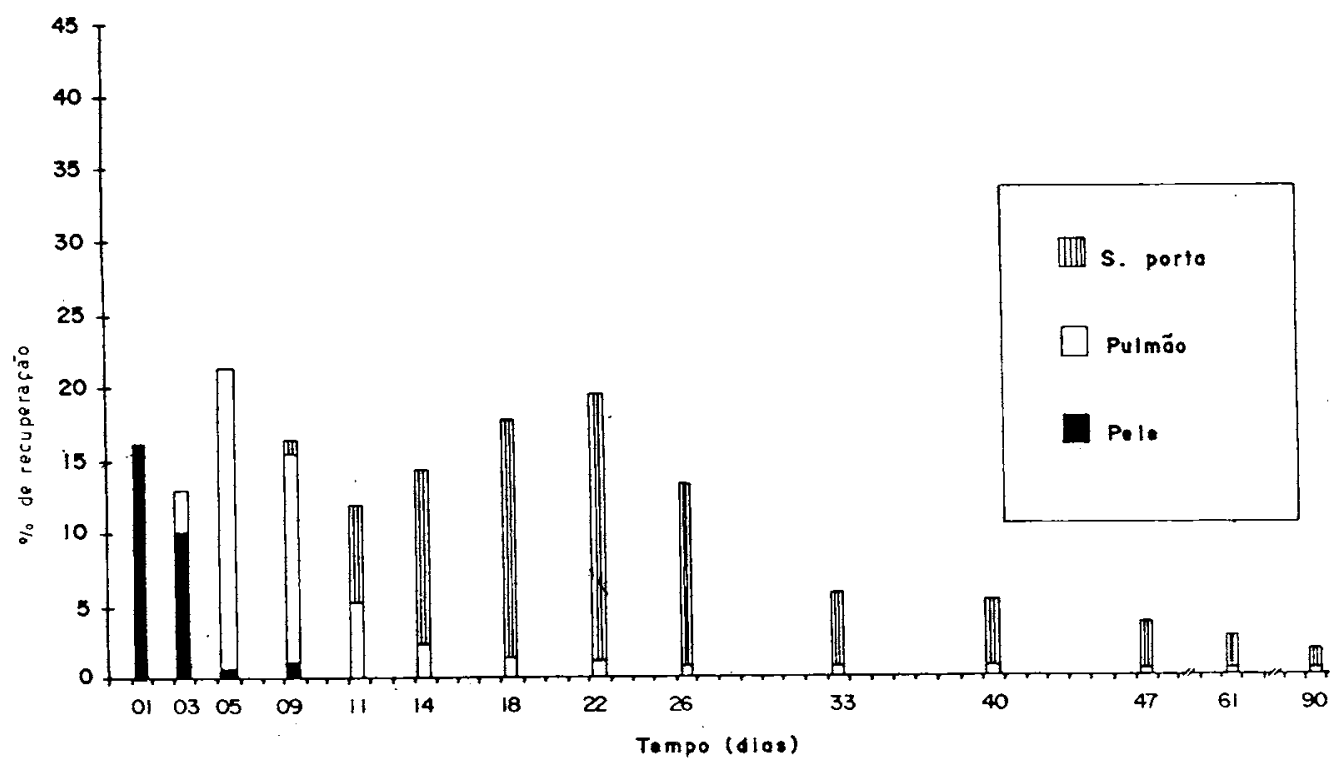

GRÁFICO 4 - Porcentagens médias da recuperação total de parasitos da pele, pulmões e sistema porta, oriundos de cercárias, da cepa SJ do S. mansoni, irradiadas com $3 \mathrm{Krad}$, obtidas em camundongos infectados transcutaneamente com cerca de 465 cercárias. 
CARDOSO, G. de S. \& COELIIO, P.M.Z. - Schistosoma mansoni: aspectos quantitativos da fertilidade e sobrevida de vermes oriundos de cercárias irmadiadas com 3 Krad, cm camundongos. Rev. Insl. Med. Irop. S. Paulo, 32(1):28-35, 1990.

tos a ccrcárias irradiadas com $3 \mathrm{Krad}$, lando um pereentual de apenas 1,9\% para a presença de ovos (mortos) no intestino e fígado desse grupo de camundongos.

\section{Recuperação total dos parasitos}

Nos gráficos 1, 2, 3 e 4 estão representados as porcentagens médias totais de recupcração de parasitos oriundos de cercárias, das cepas LE e SJ do S. mansoni, não irradiadas c irradiadas $\operatorname{com} 3$ Krad de radiação gama proveniente de Co-60.

Os resultados são a média da recuperação de parasitos obtidos da pele, pulmōes e sistema porta de seis (6) camundongos de cada grupo sacrificados a cada dia dos experimentos, levando-se em conta os tempos de infeç̧ão. Os pereentuais são calculados em relação aos números de cercárias infectantes para cada infecção.

\section{Relação macho/fêmea}

Na tabela 1, temos o número total de vermes adultos recuperados $\mathrm{c}$ as respectivas distribuiçôes $\mathrm{cm}$ machos e fêmeas para cada uma das infecçóes com cercárias não irradiadas e irradiadas com 3 Krad em ambos os experimentos, com as cepas

\section{LE c SJ do S. mansoni.}

Os resultados mostram que a relação macho/fêmea dos vermes irradiados com $3 \mathrm{Krad}$, de ambas as cepas, sempre se manteve acima de 1 até 061 dia de observação após a infecção e, somente no $90^{\circ}$ dia, essa relação tornou-se inferior à unidade, concluindo-se que os vermes machos são mais susceptíveis à irradiaçăo gama, sendo que o efeito somente se torna evidente após o $61^{\circ} \mathrm{de}$ infeção (cepa SJ).

\section{DISCUSSÃO}

Como pode ser observado nos gráficos 1,2 , 3 e 4 , a recuperação a nível de pele, pulmões e sistema porta dos parasitos irradiados e controles, cepas LE e S.J de S. mansoni, mostra claramente um decréscimo da população dos parasitos irradiados com $3 \mathrm{Krad}$, tanto a nível da pele e pulmóes, como no sistema porta, ocorrendo uma certa estabilidade da população, a partir do $33^{\circ}$ dia de infeção, notadamente na cepa LE, até o final das obscrvações $\left(90^{\circ}\right.$ dia).

O cécito da dose de 3 Krad de radiação gama sobre a fertilidade das fêmeas foi avaliado através do oograma que detectou a presença de ovos $\mathrm{cm}$

\section{TABELAA 1}

Distribuição de vermes adultos machos c fêmeas c a relação macho/fêmea cncont rada respectivamente en canundongos infectados transcutancamente com cerca de 450 cercárias não irradiadas e irmadiadas com $3 \mathrm{Krad}$ (das cepas LIE c S.J de Schistosoma mansoni).

\begin{tabular}{|c|c|c|c|c|c|c|c|c|c|c|}
\hline & & \multicolumn{3}{|c|}{$18^{\circ} \mathrm{ao} 47^{\circ} \mathrm{dia}^{*}$} & \multicolumn{3}{|c|}{$61^{12} \mathrm{diat}^{* *}$} & \multicolumn{3}{|c|}{$90^{0} \mathrm{dia}^{* *}$} \\
\hline & & $\begin{array}{c}\text { Total } \\
\text { de } \\
\text { Machos }\end{array}$ & $\begin{array}{c}\text { Tolal } \\
\text { de } \\
\text { rêncas }\end{array}$ & $M / F$ & $\begin{array}{c}\text { Total } \\
\text { de } \\
\text { Machos }\end{array}$ & $\begin{array}{l}\text { Total } \\
\text { de } \\
\text { Femeas }\end{array}$ & $\mathrm{M} / \mathrm{F}$ & $\begin{array}{c}\text { Total } \\
\text { de } \\
\text { Machos }\end{array}$ & $\begin{array}{l}\text { lotal } \\
\text { de } \\
\text { lêncas }\end{array}$ & $\mathrm{M} / \mathrm{I}$ \\
\hline CEPA & Controle & 1683 & 1145 & 1,47 & - & - & - & - & - & - \\
\hline LE & $3 \mathrm{Krad}$ & 154 & 86 & 1,79 & 36 & 22 & 1,64 & 30 & 47 & 0,64 \\
\hline CEPA & Controle & 1747 & 845 & 2,07 & - & - & - & - & - & - \\
\hline $\mathrm{SJ}$ & $3 \mathrm{Krad}$ & 125 & 61 & 2,05 & 28 & 18 & 1,55 & 12 & 24 & 0,50 \\
\hline
\end{tabular}

Observaçōcs: * 36 camunơongos ** 4 camundongos

$$
\mathrm{M} / \mathrm{F}=\text { relação Macho/Pêmca }
$$


apenas dois (2) de um total de 105 camundongos examinados, dando um percentual de $1,9 \%$. Foram encontrados 24 e 27 ovos (mortos), respectivamente no $47^{\circ}$ e $61^{\circ}$ dia após a infecção, no intestino e fígado de ambos os camundongos infectados com ccrcárias da cepa LE. Já nos camundongos controles, de ambas as cepas, foram detectados inúmeros ovos viáveis e em todos os estádios evolutivos, tanto no intestino como no fígado examinados no $40^{\circ}$ e $47^{\circ}$ dia após a infecção.

Todos os ovos encontrados nos camundongos expostos a cercárias irradiadas estavam mortos e, de acordo com BOROS \& WARREN ${ }^{3}$, esses ovos não induzem alterações patológicas, pois scria a sccreção do miracídio (o antígeno solúvel do ovo) o clemento fundamental na patologia da equistossomose. De fato, o fígado e intestino dos camundongos infectados com cercárias irradiadas com $3 \mathrm{Krad}$, inclusive nos dois que apresentaram ovos mortos, cstavam com uma aparência macroscópica normal.

Além do encontro de ovos (mortos) $\mathrm{cm}$ apenas $1,9 \%$ dos camundongos examinados, foram vistos diversos casais de vermes adultos irradiados com $3 \mathrm{Krad}$, de ambas as cepas, cm cópula, donde se conclui que a radiação gama, nessa close, torna a grande maioria dos vermes adultos sexualmente cstéreis. Isto está de acordo com VILLELLA et al. $^{12}$, que observaram que os poucos vermes que se desenvolveram de cercárias, de uma cepa de $S$. mansoni de Porto Rico mantida $\mathrm{em} \mathrm{B.} \mathrm{glabrata,}$ irradiadas com 3.000 rep (aproximadamente 3 Krad) de radiação gama proveniente de Co-60, cram estércis.

$O$ efeito da radiação ionizante, em doses equivalentes ou aproximadas a $3 \mathrm{Krad}$ de radiação gama, sobre a fertilidade das fêmeas, provavelmente está relacionado com as alteraçôes morfológicas por cla induzidas nos órgãos reprodutivos de machos c fêmeas. Assim, PERLOWAGORASZUMLEWICZ ${ }^{9}$ observou que vermes irradiados com $2.000 \mathrm{r}$ e $2.500 \mathrm{r}$ (aproximadamente $2 \mathrm{e}$ 2,5 Krad) de raios X eram estéreis e se apresentavam atrofiados, sendo que a maioria dos machos mostrava tubos digestivos anormais. VILLELLA \& WEINBREN ${ }^{13}$ observaram que a radiação gama proveniente de Co- 60 nas doses de $2.000 \mathrm{c}$ $2.500 \mathrm{rad}$ (equivalente a 2 e $2,5 \mathrm{Krad}$ ) produz malformações nas estruturas reprodutivas de vermes de ambos os sexos que os tornam sexualmente estéreis e, segundo os autores, as fêmcas estéreis apresentavam atrofia geral do corpo e órgãos reprodutivos malformados. BICKLE et al. ${ }^{2}$ observaram que todas as fêmeas irradiadas com 2,3
Krad, coradas com carmin, não possuíam ovários visíveis e que somente $43 \%$ dos machos corados tinham testículos visíveis.

PERLOWAGORA-SZUMLEWICZ ${ }^{8}$ adverte ainda para o fato de que vermes machos $\mathrm{e}$ fêmeas, provenientes de cercárias irradiadas com $2.000 \mathrm{r}$ (aproximadamente $2 \mathrm{Krad}$ ) de raios X, são capazes de por ovos quando copulam com vermes normais e, portanto, a introdução de cercárias atenuadas pela irradiação, durante o processso de imunização, poderia representar uma ameaça à segurança do hospedeiro. BICKLE et al. ${ }^{2}$ observaram que vermes irradiados com 2,3 Krad de radiação gama, de ambos os sexos, foram capazes de reproduzir satisfatoriamente na presença de parceiros não irradiados, quando camundongos foram infectados com 1.200 cercárias machos irradiadas juntas com 50 fêmeas normais ou infectados com 50 cercárias machos normais juntas com 1.200 fêmeas irradiadas.

Nos resultados obtidos (gráfico 2 para a cepa LE e gráfico 4 para a SJ), verificou-se que os vermes irradiados com $3 \mathrm{Krad}$, de ambas as cepas, foram detectados no sistema porta a partir do $8^{\circ}$ dia após a infecção c os picos máximos de recuperação vcrificaram-se entre o $18^{\circ}$ e $26^{\circ}$ dias. No $26^{\circ}$ dia após a infecção, as taxas de recuperaçāo sofrem uma redução estatisticamente significativa $(\mathrm{P}<0,01)$ e a partir do $33^{\circ}$ dia elas se mantêm em uma proporção constante até o último dia de observação. Portanto, os vermes irradiados com 3 $\mathrm{Krad}$, de ambas as cepas, foram detectados no sistema porta até o $90^{\circ}$ dia após a infecção. Isto está de acordo com PERLOWAGORA-SZUMLEWICZ $^{9}$ que observou que apesar de poucos vermes irradiados com $2.000 \mathrm{r}$ (aproximadamente $2 \mathrm{Krad}$ ) de raios $X$ alcançarem o sistema porta de camundongos infectados com 300 cercárias de $S$. mansoni, cepa de Porto Rico, eles foram encontrados ainda no $200^{\circ}$ dia após a infeç̧ão. PERLOWAGORA-SZUMLEWICZ ${ }^{10}$ observou em camundongos infectados com cercárias de um sexo, cepa de Porto Rico, irradiadas com 2.000 r (aproximadamente $2 \mathrm{Krad}$ ) de raios $\mathrm{X}$ que, apesar da baixa taxa de recuperação, tanto dos vermes machos irradiados como das fêmeas irradiadas, a persistência de ambos no sistema porta mantevese até o fim das observações, que foi correspondente aos períodos de 9 e 12 meses, respectivamente.

Em nossos estudos, verificamos que os vermes adultos machos, tanto da cepa LE como da SJ, são mais sensíveis à irradiação gama (na dose de $3 \mathrm{Krad}$ ) que as fêmcas c o cfcito da radiaçāo 
sobre mortalidade dos machos em relação às fêmeas somente se torna estatisticamente significativo após o $61^{\circ}$ dia de infecção (tabcla 1). Isto está de acordo com a literatura no que diz respcito à maior sensibilidade dos vermes machos à irradiação, porém, discorda no que se referc ao tempo no qual se detecta os efeitos da irradiaçāo. Assim, PERLOWAGORA-SZUMLEWICZ ${ }^{8}$ verificou que a radiação $X$ na dose de $2.000 \mathrm{r}$ (aproximadamente $2 \mathrm{Krad}$ ) diminui o número de vermes machos até provocar proporções macho/fêmea menores que a unidade, quando normalmente csta relação é maior que 1 , concluindo que esse fenômeno pode ser atribuído à maior suscetibilidade do parasito macho aos raios $\mathrm{X}$ e também que o efeito da irradiação se faria sentir logo de início, prolongando-se até o final das observações. BICKLE et al. ${ }^{2}$ observaram que os vermes machos foram mais sensiveis do que as fêmeas aos efeitos da irradiação, já no $28^{\circ}$ dia de obscrvação, em camundongos infectados intramuscularmente com esquistossômulos irradiados $2,3 \mathrm{Krad}$ de radiação gama proveniente de Co-60.

Em um experimento (a ser publicado) foi verificado que camundongos isogênicos $\mathrm{Balb} / \mathrm{c}$ infectados transcutaneamente com cerca de 445 cercárias irradiadas com $3 \mathrm{Krad}$, da cepa LE do S. mansoni, desenvolveram uma imunoproteção de, aproximadamente, $70 \%$, a uma reinfecção desafio com cerca de 57 cercárias normais não irradiadas administrada no $70^{\circ}$ dia após a primeira infecção. Este resultado associado aos achados do presente estudo leva-nos a pressupor que a longa sobrevida, no sistema porta de camundongos, dos vermes estéreis irradiados com $3 \mathrm{Krad}$ poderia manter por longo tempo uma imunidade contra infecções cercarianas, sem as implicaçōes patológicas devidas ao granuloma produzido por ovos viáveis.

\section{SUMMARY}

\section{Schistosoma mansoni: quantitative aspects of the fertility and survival of worms obtained from irradiated cercariae (3 Krad), in mice}

The effect of gamma irradiation on the fertility of female mice, as well as the survival of worms in their portal system, have becn observed in four groups of outbred albino mice (Mus musculus), experimentally infected with ca 450 cercariae of Schistosoma mansoni (LE and SJ strains), by transcutaneous route. The cercariae used were a) non-irradiated (control groups), and b) irradiated with $3 \mathrm{Krad}$ of gamma irradiation ( $\mathrm{Co}-60)$. From the $33^{\text {rd }}$ day on, some estability in the population of surviving worm could be observed. This population remained constant till the end of the observation period $\left(90^{\text {th }}\right.$ day), notedly in relation to the LE strain. Thus, it was concluded that gamma irradiation (at the dose of $3 \mathrm{Krad}$ ) is able to hinder the worm egg production in $98.1 \%$ of the infected mice. Further, it was observed that the few detected eggs were dead. Females were found to be more resistant to irradiation. The irradiation effect on the mortality of male worms was statistically significant scarcely from the $61^{\text {st }}$ day on. The long period of permanence of the sterile adult irradiated worms in the portal system of mice and their probable involvement in the development of immunoprotection (the so-called concomitant immunity, without the immunopathological involvements for the host) are here discussed.

\section{AGRADECIMENTOS}

Os autores agradecem a Adelino Ferreira, Alberto Geraldo dos Santos, Alice Neni Faria, Atenágoras Nascimento Silva, José de Souza Filho, Maurício Virícimo dos Santos e Zenir de Souza pela assistência técnica.

Este trabalho foi financiado, $\mathrm{cm}$ parte, pelo CNPq, FINEP e CPqUFMG.

\section{REFERENCIAS BIBLIOGRÁFICAS}

1. BARIBOSA, M.A.; PELLEGRINO, J.; COELHO, P.M.Z. \& SAMPAIO, I.B.M. - Quantitative aspects of the asynchronism in the development of Schistosoma mansoni in mice. Rev. Inst. Med. 1rop. S. Paulo, 20:121-132, 1978 .

2. BICKLE, Q.D.; DOBINSON, T. \& JAMES, E.R. - The effects of gamma-irradiation on migration and survival of Schistosoma mansoni schistosomula in mice. Parasitology, 79:223-230, 1979.

3. BOROS, D.L. \& WARREN, K.S. - Delayed hypersensitivity-type granuloma formation and dermal reaction induced and elicited by a soluble factor isolated from Schistosoma mansoni eggs. J. Parasit., 132:488, 1970.

4. IREITAS, J.R. - Kitmo de crescimento de Biomphalaria glabrala (Say, 1818). Padronização da técnica de criação. Belo Horizonte, 1973. ('Tese de Doutoramento - Instituto de Ciências Biológicas da Universidade Federal de Minas Gcrais). 108 pp.

5. PELLEGRINO, J. \& KATZ, N. - Schistosoma mansoni: some biological aspects in connection with 
CARDOSO, G. de S. \& COELHO, P.M.Z. - Schistosoma mansoni: aspectos quantitativos da fertilidade e sobrevida de vermes oriundos de cercárias irradiadas com $3 \mathrm{Krad}, \mathrm{cm}$ camundongos. Rev. Inst. Med. trop. S. Paulo, 32(1):28-35, 1990.

experimental chemotherapy. 'Trans. roy. Soc. trop. Med. IIyg., 63:568-575, 1969.

6. PELLEGRINO, J.; OLIVIEIRA, C.A.; İARIA, J. \& CUNHA, A.S. - New approach to the screcning of drugs in experimental schistosomiasis mansoni in micc. Amer. J. 1rop. Med. Hyg., 11:201-215, 1962.

7. PELLEGRINO, J. \& SIQUEIR A, A.I. - 'Tćcnica de perfusão para colheita de Schistosoma mansoni $\mathrm{cm}$ cobaias experimentalmentc infestadas. Rev. bras. Malar., 8:589-597, 1956.

8. PERLOWAGORA-SZUMLIEWICZ, A. - O papel das ccrcárias atcnuadas na imunização cfctiva contra o Schislosoma mansoni. Rev. bras. Malar., 16:505-525, $1964 \mathrm{a}$.

9. PERLOWAGORA-SZUMLEWICZ, A. - Studics on acquired resistance to Schistosoma mansoni in micc exposed to X irradiated cercariac. Bull. WId. IIIth. Org., 30:401-412, 1964b.
10. PERLOW AGORA-SZUMLIWWICZ, $\wedge$. - Studics on acquired resistance to Schistosoma mansoni in mice exposed to $X$ irradiated cercariac of one sex. Rev. Inst. Med. trop. S. Paulo, 8:203-218, 1966.

11. SNLDECOR, G.W. \& COCHRAN, W.G. - Two way classification. In: SNEDECOR, G.W. \& COCIHRAN, W.G. - Statistical methods. $6^{\text {th }} \mathrm{cd}$. lowa, The State University Press. 1971. v.2, chapter 11, p.327-329.

12. VILLLLLA A, J.B.; GOMIBLRG, II.J. \& GOULD, S.E. Immunization to Schistosoma mansoni in mice inoculated with radiated, cercariac. Science, 1.34:1073-1075, 1961

13. VILLLLL $\Lambda$, J.B. \& WEINIBREN, M.P. - $\Lambda$ bnormalitics in adult Schistosoma mansoni developed from gamma-irradiated cercariac. J. Parasit., 51:42, 1965.

Recebido para publicação $\mathrm{cm} 26 / 6 / 1989$. 